A. Tyagi ${ }^{1}$, I. Boxx ${ }^{2}$, S. Peluso ${ }^{1}$, R. Shupp ${ }^{1}$, J. O’Connor ${ }^{1}$.

${ }^{1}$ Department of Mechanical Engineering, The Pennsylvania State University

${ }^{2}$ Institute for Combustion Technology, The German Aerospace Center.

"Structure of Flames in Flame Interaction Zones", 2018 AIAA Aerospace Sciences Meeting, AIAA SciTech Forum Paper \# AIAA 2018-0161

The AIAA version of the paper is accessible at https://doi.org/10.2514/6.2018-0161

On the AIAA web page https://arc.aiaa.org/doi/10.2514/6.2018-0161 the interested reader can find other material published by AIAA 


\title{
Structure of Flames in Flame Interaction Zones
}

\author{
Ankit Tyagi ${ }^{1}$ \\ The Pennsylvania State University, University Park, PA 16802 \\ Isaac Boxx ${ }^{2}$ \\ DLR, German Aerospace Center, Stuttgart, Germany, 70596 \\ and \\ Stephen Peluso ${ }^{3}$, Ryan Shupp ${ }^{4}$, and Jacqueline O'Connor ${ }^{5}$ \\ The Pennsylvania State University, University Park, PA 16802
}

Two identical burners with variable burner separations are used to investigate the dynamics of interacting flames. The presence of adjacent flames in large scale combustion devices influences the structure and dynamics of the flames, and understanding the sensitivity of flames to these interactions is vital for local and global flame characterization. The behavior of the flame in the interaction zone is dependent on a number of operating parameters, including burner separations, inlet bulk flow velocities, and flame stabilization or flame shape. High-repetion-rate $\mathrm{CH}^{*}$ chemiluminescence and $\mathrm{OH}-$ planar laser-induced flourescence measurements are performed to obtain the flame structure and flame-front locations. These measurement techniques allow for the determination of how varying fluid-dynamic and geometric parameters change the behavior of these flames in the flame interaction zones. We also quantify global metrics like flame surface density, global consumption speed, and flame curvature PDFs to understand the impact of flame interaction.

\section{Nomenclature}

$\begin{array}{ll}A_{\bar{c}} & =\text { progress variable contour based flame area } \\ \text { FOV } & =\text { field-of-view } \\ \text { FSD } & =\text { flame surface density } \\ \text { OH-PLIF } & =\text { OH-planar laser-induced fluorescence } \\ \text { PDF } & =\text { probability density function } \\ R e_{t} & =\text { turbulent Reynolds number } \\ S & =\text { burner centerline separation } \\ \text { S-PIV } & =\text { stereoscopic - particle image velocimetry } \\ S_{T, G C} & =\text { global consumption speed } \\ U & =\text { bulk flow velocity } \\ \bar{c} & =\text { averaged-progress variable } \\ d & =\text { Cohen's d-metric } \\ l & =\text { integral length scale } \\ l_{f} & =\text { flame thickness } \\ \dot{m}_{R} & =\text { premixed gas mass flow rate } \\ s & =\text { arc-length along the flame front } \\ S_{L} & =\text { laminar flame speed } \\ u^{\prime} & =\text { magnitude of RMS of fluctuating velocity }\end{array}$

\footnotetext{
${ }^{1}$ Graduate student, Mechanical Engineering, The Pennsylvania State University, AIAA Student Member

${ }^{2}$ Senior Scientist, Institute for Combustion Technology, AIAA Member

${ }^{3}$ Assistant Research Professor, Mechanical Engineering, The Pennsylvania State University

${ }^{4}$ Undergraduate student, Mechanical Engineering, The Pennsylvania State University

${ }^{5}$ Assistant Professor, Mechanical Engineering, The Pennsylvania State University, AIAA Member

American Institute of Aeronautics and Astronautics
} 


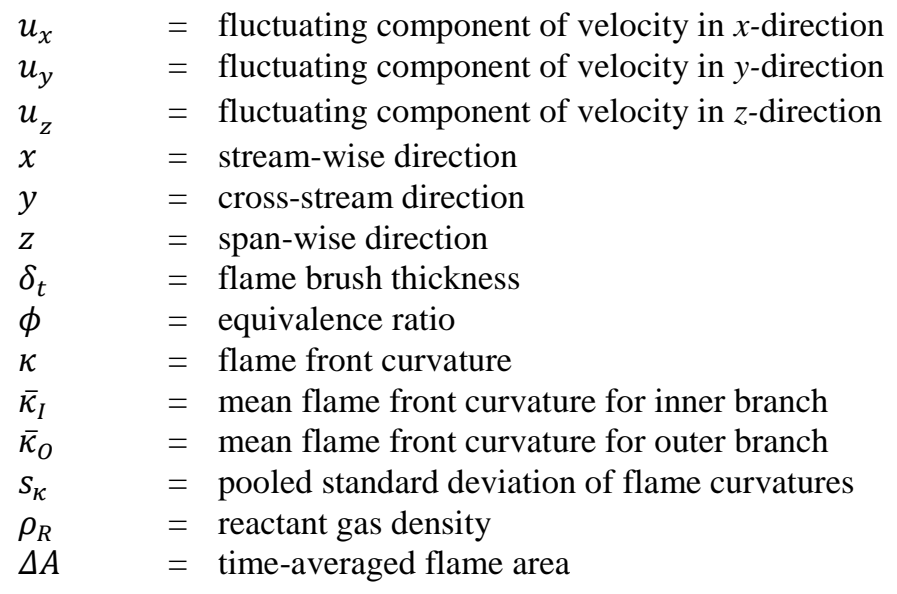

\section{Introduction}

$\mathrm{F}$ LAME interaction between adjacent flames occurs in a large number of combustion configurations, including jet engine combustors and augmentors, power generation gas turbines, and industrial boilers and furnaces. In all of these cases, adjacent flames have both interacting flowfields as well as scalar fields, and the structure and dynamics of adjacent flames is dependent on both these interacting fields. The goal of this work is to characterize the behavior of the interaction zone between two interacting flames in a number of flame configurations, including Bunsen, M-, and V-flames, to understand the structure of the flame in this interaction region. Results from chemiluminescence imaging are also discussed, as this diagnostic is used extensively to investigate flames in practice.

A number of previous studies have considered the dynamics of flames in the interaction zone, although the majority of these studies have focused on flames undergoing thermoacoustic instability. Experiments by Reuter and coworkers [1-4] showed that variations in the amplitude of thermoacoustically-driven flame area fluctuations due to the level of interaction between the two flames could impact the feedback mechanism. The differences in total flame area and the resultant flame area fluctuations in the experiments by Reuter and coworkers is congruent with other two-V-flame experiments from Francois et al. [5] and Dunstan et al.[6,7]. More recent studies have focused on flame interaction in annular and can-annular gas turbine combustors [8-13]. In these configurations, three-dimensional effects are important and the flames are typically swirl-stabilized, introducing a very complex flow interaction mechanism that is beyond the scope of this work. However, a number of findings from these studies can be generalized and could have an impact on the way we understand flame interaction in general.

Studies from Worth and Dawson [10-12] and Samarasinghe and coworkers [8, 9, 14] have both noted that flame interaction in gas turbine configurations enhances the turbulent flame brush and the chemiluminescence signal in the flame interaction region. OH-planar laser-induced fluorescence (OH-PLIF) and tomographic chemiluminescence imaging were used to investigate the interaction. At the closer flame spacing, the interaction between the flames results in a wider and taller flame brush than the interaction with the wall, as well as a more intense chemiluminescence signal from the interaction zone. Aside from visualization of the enhancement of the flame brush and chemiluminescence in the interaction region, Worth and Dawson quantified the effect of flame spacing by using PDFs of the flame curvature from OH-PLIF imaging. As the flame separation distance decreases, the PDF shifts towards more negative curvatures, similar to the results from Dunstan et al. [6,7]. This shift is a result of the increased frequency of local flame interaction events that enhance cusping, which has a negative flame curvature. Similarly, acoustically-driven fluctuations in the flame result in smaller coherent heat release rate fluctuations in cases with more flame interaction because of the more frequent flame interactions. Additionally, the flame surface density fluctuations increased at a greater rate than heat release rate fluctuations because of higher levels of mean flame stretch. The enhanced flame interaction increased nonlinearity in the flame response to input fluctuations because of frequent flame annihilation and sudden flame area fluctuations, as noted in Chen et al. [15].

The local dynamics of interacting flames have mostly been investigated in DNS. Flames can locally interact in two ways. Dunstan et al. [6, 7] define these as normal and counternormal interactions. Normal interactions are those where flames propagate towards each other and a layer of reactants is consumed between the flames as the interaction occurs. Counternormal interactions are those where the products-side of the flames interact. For both of these types of interactions, three topologies of interaction processes are possible: convex, tunnel-closure, and pocket burnout processes. Similar flame-interaction topologies were recently described by Griffiths $e t$ al. [16] by a spectrum of shape

American Institute of Aeronautics and Astronautics 
factors that quantify the surface topology and evolution; both normal and counternormal interactions can be described by these shape factors.

Taken together, these interactions can have significant implications for global flame characteristics, including flame area, heat release rate, consumption speed, and sound production. Flame interaction events can cause significant and sudden variations in flame area. Chen et al. [15] quantified the variation in flame area with a DNS of a tunnel closure and subsequent pocket formation burnout. Their work showed that as a tunnel closure event begins, a sharp decrease in flame area results from the annihilation of the flame during the interaction and subsequent pocket burnout. The global heat release trails the variation in flame area due to stretch effects. Flame speed can also be varied by the rapid fluctuations in flame area and flame stretch that occur during flame interaction events. Chen et al. [15] showed a four-fold increase in density-weighted displacement speed during pocket burnout due to preferential diffusion effects that occur locally during flame interaction. Sun and Law [17] also calculated increases in flame propagation speed during pocket burnout. Consumption speed increases have also been reported by Ranganath and Echekki [18], Chen and Sohrab [19], and Ranganath and Echekki [20].

These limited studies have shown that the zone in between flames can be quite dynamic, and warrants further investigation. The goal of this study is to document the dynamics of the flames and flow in this inter-flame region and determine how these dynamics change as a function of flame shape, Reynolds number, and flame spacing.

\section{Experimental Configuration}

\section{A. Experimental Facility}

The experimental facility consists of two identical burners with $100 \mathrm{~mm} \times 10 \mathrm{~mm}$ exit planes and, in some configurations, $3.175 \mathrm{~mm}$ diameter circular bluff-bodies, attached along the $100 \mathrm{~mm}$ length direction (Figure 1). The burners are comprised of two stacked sections that are $178 \mathrm{~mm}$ and $160 \mathrm{~mm}$ tall. The first section contains the inlet for the incoming flow and a ceramic honeycomb layer, and the second section contains an additional layer of honeycomb and two perforated plates. A premixed natural gas and air mixture flows through the two layers of ceramic honeycomb inside the burners, which condition the flow before the mixture reaches the burner exit plane. The two perforated plates placed at $30 \mathrm{~mm}$ and $10 \mathrm{~mm}$ upstream of the burner exit plane are used to create turbulence in the flowfield. The perforated plates have a hole diameter of $3.175 \mathrm{~mm}$, with an open area of $40 \%$. The specifics of the perforated plates are chosen based on a study by Roach [21], which describes empirical correlations for calculating turbulence characteristics of nearly isotropic, homogeneous turbulent flows, generated by the use of grids. With the perforated plate combinations used as described above, we are able to achieve averaged non-reacting flow turbulenceintensities of $18 \%$ in the flowfields. These turbulence intensities are normalized by the bulk flow velocities.

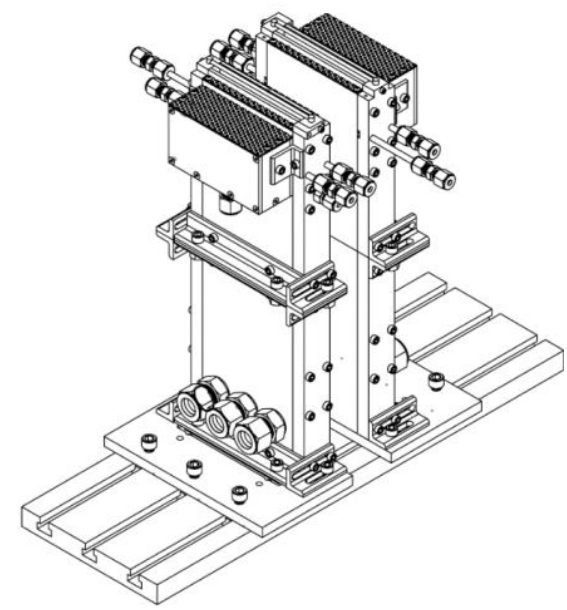

(a) Isometric view

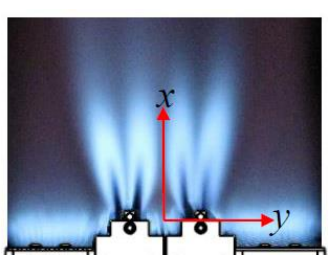

(b) Front view

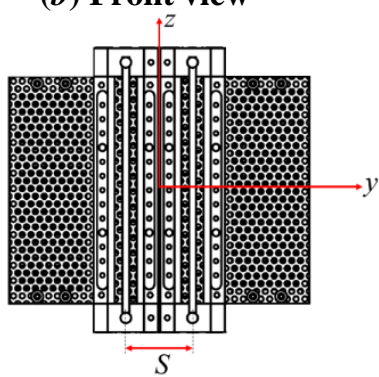

(c) Top view

Figure 1: Sketch of the experimental facility: $(a)$ isometric view of the two separated burners, $(b)$ the front view with a superimposed image of bluff body flames and all pilot flames in operation, and $(c)$ the top view defining the separation between burner centerlines. 
This modular design of the burners allows for using perforated plates of different sizes and open areas, generating a variety of turbulence intensities. The bluff bodies can be removed from the burners, which permits for variation in flame shape. The large aspect ratio of the burner exit plane allows for a negligible mean velocity gradient in the $z$ direction and formation of a statistically two-dimensional premixed turbulent flame along the center of the burner at different flame shapes and flow conditions. To achieve Bunsen flames stabilization at bulk flow velocities larger than $5 \mathrm{~m} / \mathrm{s}$, two types of pilot flames are used: small "anchoring" pilots, which are located close to the exit of the burners and help anchor the flames on the experiment, and larger "back-support" pilots, which provide adiabatic or superadiabatic combustion products around the flames. Air and fuel flow through the main burners are measured with thermal mass flow meters (Teledyne Hastings Instruments HFM-205 and HFM-201). The air and fuel flow through the pilot flame flow circuits are measured using calibrated rotameters. The burners are mounted to a small mill stage, which allows for measurement access to differernt locations in the flames while keeping the lasers and cameras stationary. The separation distance between the burners can be varied by sliding each burner independently on the top of the mill stage. For the rest of the paper, the burner separation (used interchangeably with flame spacing) is defined as the distance between the burner centerlines, as marked in Figure 1(c).

\section{B. Experimental Diagnostics and Data Processing}

\section{OH-Planar Laser-Induced Flourescence and $\mathrm{CH}^{*}$ Chemiluminescence}

$\mathrm{OH}$-planar laser induced fluorescence (OH-PLIF) is performed at a repetition rate of $10 \mathrm{kHz}$ to obtain instantaneous flame-front locations. The OH-PLIF system consists of a $532 \mathrm{~nm}$ Nd:YAG laser (Edgewave) pumping a dye laser (Sirah Credo). A sketch of the OH-PLIF and stereoscopic-particle image velocimetry (s-PIV) is shown in Figure 2(a). The maximum power output from the Nd:YAG laser at $10 \mathrm{kHz}$ repetition-rate is $53 \mathrm{~W}$, which results in a $0.3 \mathrm{~mJ} / \mathrm{pulse}$ output from the dye laser. The output from the dye laser is tuned to the $\mathrm{Q}_{1}(6)$ line of the $\mathrm{A}^{2} \Sigma^{+} \leftarrow \mathrm{X}^{2} \Pi(1$ 0 ) band to excite the $\mathrm{OH}$ radicals at $282.94 \mathrm{~nm}$. The UV beam from the dye laser is passed through a periscope and a set of three cylindrical lenses to obtain a collimated sheet with an approximate height of $21 \mathrm{~mm}$. The signal from the excited $\mathrm{OH}$ radicals is acquired using a CMOS sensor camera (Photron FASTCAM SA1.1), coupled with an external intensifier (LaVision HS-IRO) and a $100 \mathrm{~mm} \mathrm{f} / 2.8 \mathrm{UV}$ lens (Cerco). The lens is equipped with a high transmissitivity interference filter(LaVision $1108760 \mathrm{VZ}$ ). The field of view (FOV) achieved through this setup is $50 \mathrm{~mm} \times 100 \mathrm{~mm}$. The intensifier gate is set at $100 \mathrm{~ns}$ to reduce background flame luminosity.

The camera setup for performing $\mathrm{CH}^{*}$ chemiluminescence is identical to the setup for the OH-PLIF, except we use a $50 \mathrm{~mm} \mathrm{f} / 1.4$ (Nikon AF NIKKOR) lens and a $430 \mathrm{~nm}$ bandpass optical filter (Andover Corporation, Bandpass Filter, FWHM $10.0 \mathrm{~nm}$ ). The intensifier gate is set at $75000 \mathrm{~ns}$ in order to obtain sufficient signal from the line of sight integrated emission of $\mathrm{CH}^{*}$ radicals.

\section{OH-PLIF image bianrization and edge detection}

The OH-PLIF images are binarized using a dynamic thresholding technique that reduces the sensitivity of the calculation to variations of the image in each frame. First, the images are corrected for laser sheet intensity variations. The sheet correction profile is collected from averaging OH-PLIF images of the anchoring pilot flames. Second, a median filter is utilized on the sheet corrected image to remove speckle noise in the image. A bilateral filtering is performed on the median filtered image to smooth the discrete intensity changes in the image. Finally, Otsu's method [22] is used to perform thresholding to obtain a binarized image. The flame edges are obtained by tracing the edges of the binarized images using the 'bwboundaries' function in MATLAB. Cropping of edges is performed on raw traced edges to isolate flame edges from UV-sheet boundaries.

\section{Flame curvature measurement}

Flame curvature is calculated using the flame edges from the flame edge detection method. The raw flame edges are smoothed using the Savitzky-Golay [23] filtering method. The Savitzky-Golay filtering method used here involves a third order polynomial fit for sets of 15 pixels, along the entire flame edge. First and second partial derivatives of the smooth edge are calculated based on numerical approximations and used to calculate the curvature of the flame edge. 


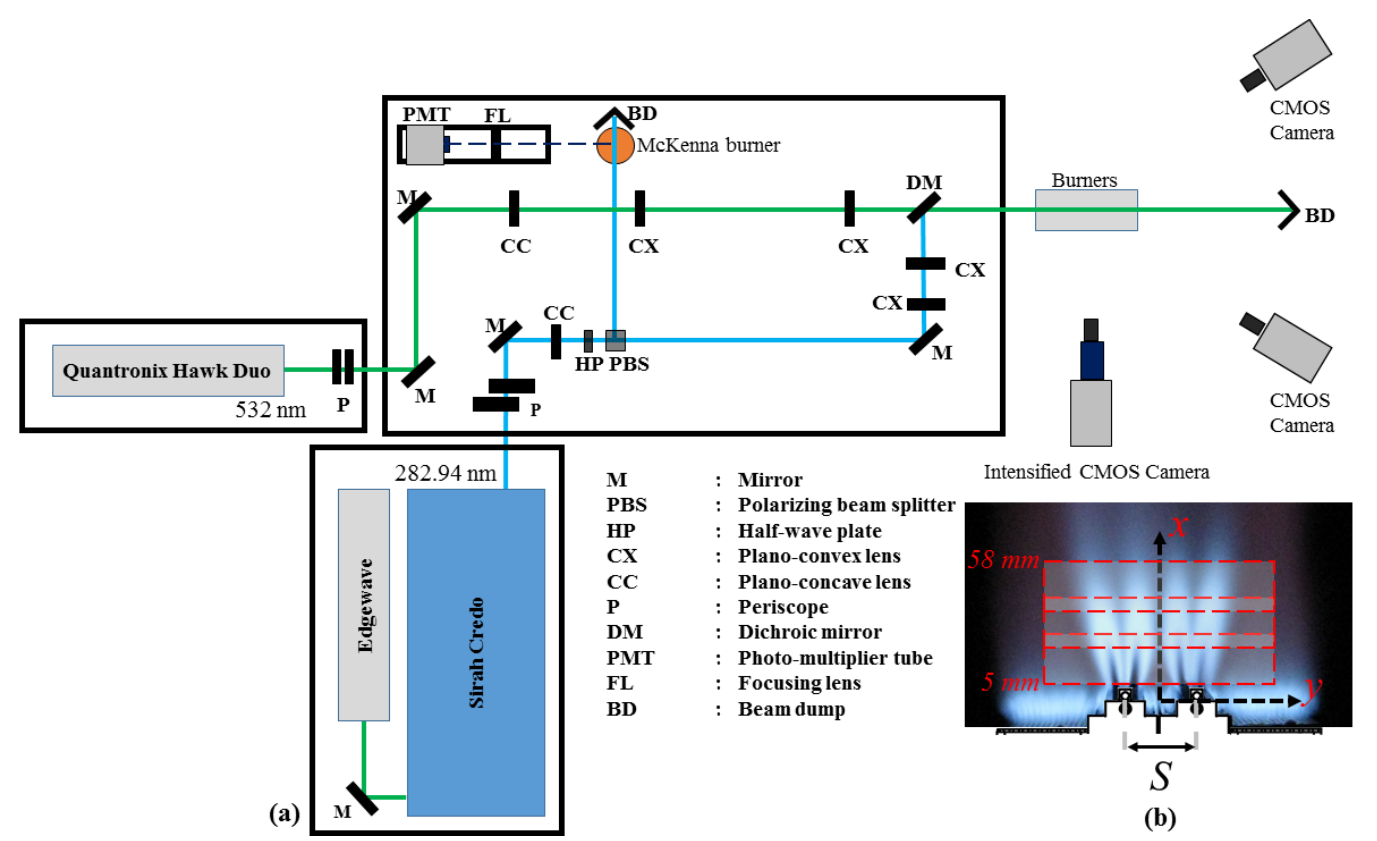

Figure 2: (a) Sketch of the OH-PLIF and s-PIV system (top view), and (b) three FOVs overlayed on top of bluff-body flames with all pilot flames.

\section{Results}

\section{A. Test matrix and flame shapes}

Table 1 provides the operating conditions in this study. Both bluff-body stabilized and pilot-flame assisted Bunsen flames are investigated, with variations in the burner separations and bulk flow velocities. In the bluff-body case, the $3.175 \mathrm{~mm}$ circular bluff body on the burner exit blocks approximately $32 \%$ of the open area for reactant gas flow, leaving approximately $34 \%$ open area on either side of the rod. With the use of anchoring pilot flames and backsupport pilot flames, flames attach not only to the bluff-bodies, but also to the burner edges. Due to this additional attachment of the flames, the time-averaged shape of the flame is an M-flame. In order to obtain the V-flame, the bluff-body stabilized flames are operated at leaner equivalence ratios and without any assistance of the pilot flames. For all these flames, OH-PLIF measurements are performed in three different viewing windows: near the burner exit (I), the interaction zone (II), and the flame tip region (III), with a $5 \mathrm{~mm}$ overlap between windows. $\mathrm{CH}^{*}$ chemiluminescence imaging captures the entire flame length, as shown in Figure 2(b).

GRIMECH 3.0 in Chemkin is used to obtain the unstretched laminar flame speed $\left(s_{L}\right)$ and the laminar flame thickness $\left(l_{f}\right)$ of a methane-air premixed flame at $1 \mathrm{~atm}$ and $300 \mathrm{~K}$. The values of $s_{L}$ and $l_{f}$ at $\Phi=0.9$ and $\Phi=1$ are $0.36 \mathrm{~m} / \mathrm{s}$ and $0.703 \mathrm{~mm}$, and $0.4 \mathrm{~m} / \mathrm{s}$ and $0.697 \mathrm{~mm}$, respectively. Turbulence characterization is perfomed near the burner exit using stereoscopic-particle image velocimetry (s-PIV) at non-reacting flow conditions. The turbulence intensity and integral lengthscale are calculated at $8 \mathrm{~mm}$ above the exit of the burner, and the lengthscale calculation uses a spatial correlation of the axial velocity fluctuations in the axial direction. This height is chosen to avoid interference from the laser sheet reflections near the burner exit. Velocity fluctuations are calculated as the root-meansquare of the fluctuating velocity: $\left(u^{\prime}=\left\{\left(u_{x}^{2}+u_{y}^{2}+u_{z}^{2}\right) / 3\right\}^{1 / 2}\right)$.

Table 1: Operating conditions for flames studied in the paper.

\begin{tabular}{ccccccccccc}
\hline Case & $\begin{array}{c}\boldsymbol{U} \\
{[\mathbf{m} / \mathbf{s}]}\end{array}$ & $\begin{array}{c}\text { Flame } \\
\text { attachment }\end{array}$ & $\begin{array}{c}\text { Pilot } \\
\text { flames }\end{array}$ & $\boldsymbol{\Phi}$ & $\begin{array}{c}\boldsymbol{u}^{\prime} \\
{[\mathbf{m} / \mathbf{s}]}\end{array}$ & $\begin{array}{c}\boldsymbol{l} \\
{[\mathbf{m m}]}\end{array}$ & $\boldsymbol{u}^{\prime} / \boldsymbol{s}_{\boldsymbol{L}}$ & $\boldsymbol{l} / \boldsymbol{l}_{\boldsymbol{f}}$ & $\boldsymbol{R e}_{\boldsymbol{t}}$ & $\begin{array}{c}\boldsymbol{S} \\
{[\mathbf{m m}]}\end{array}$ \\
\hline $\mathrm{A}$ & 12 & Bluff-body & None & 0.9 & 2.3 & 1.6 & 6.2 & 2.3 & 254 & 30 \\
$\mathrm{~B}$ & 12 & Bluff-body & None & 0.9 & 2.3 & 1.6 & 6.2 & 2.3 & 254 & 35 \\
$\mathrm{C}$ & 12 & Bluff-body & None & 0.9 & 2.3 & 1.6 & 6.2 & 2.3 & 254 & 40 \\
$\mathrm{D}$ & 12 & Bluff-body & None & 0.9 & 2.3 & 1.6 & 6.2 & 2.3 & 254 & 45
\end{tabular}

American Institute of Aeronautics and Astronautics 


\begin{tabular}{ccccccccccc} 
E & 12 & Bluff-body & None & 0.9 & 2.3 & 1.6 & 6.2 & 2.3 & 254 & 50 \\
F & 12 & Bluff-body & None & 0.9 & 2.3 & 1.6 & 6.2 & 2.3 & 254 & 55 \\
G & 16 & Bluff-body & None & 0.9 & 2.9 & 1.8 & 8.1 & 2.6 & 376 & 55 \\
H & 12 & Bunsen & All & 1.0 & 2.3 & 1.6 & 5.6 & 2.3 & 254 & 30 \\
I & 16 & Bunsen & All & 1.0 & 2.9 & 1.8 & 7.3 & 2.6 & 376 & 30 \\
J & 20 & Bunsen & All & 1.0 & 3.7 & 1.9 & 9.3 & 2.8 & 513 & 30 \\
K & 24 & Bunsen & All & 1.0 & 4.4 & 1.8 & 10.9 & 2.6 & 560 & 30 \\
L & 28 & Bunsen & All & 1.0 & 5.1 & 1.7 & 12.7 & 2.4 & 606 & 30 \\
\hline
\end{tabular}

Figure 3 shows the premixed flame regime of the turbulent flames investigated in this study on a typical BorghiPeters diagram [24]. All of these flames are in the thin reactions zone, where, according to theory, fast chemical reactions occur in thin sheets and turbulence affects the preheat zone of the flame structure. The OH-PLIF data collected in this study reflect the theory, showing highly wrinkled, but connected, reaction zones. As we do not measure any species in the preheat zone, such as formaldehyde [25], we cannot comment on the structure of the preheat zone at these conditions.

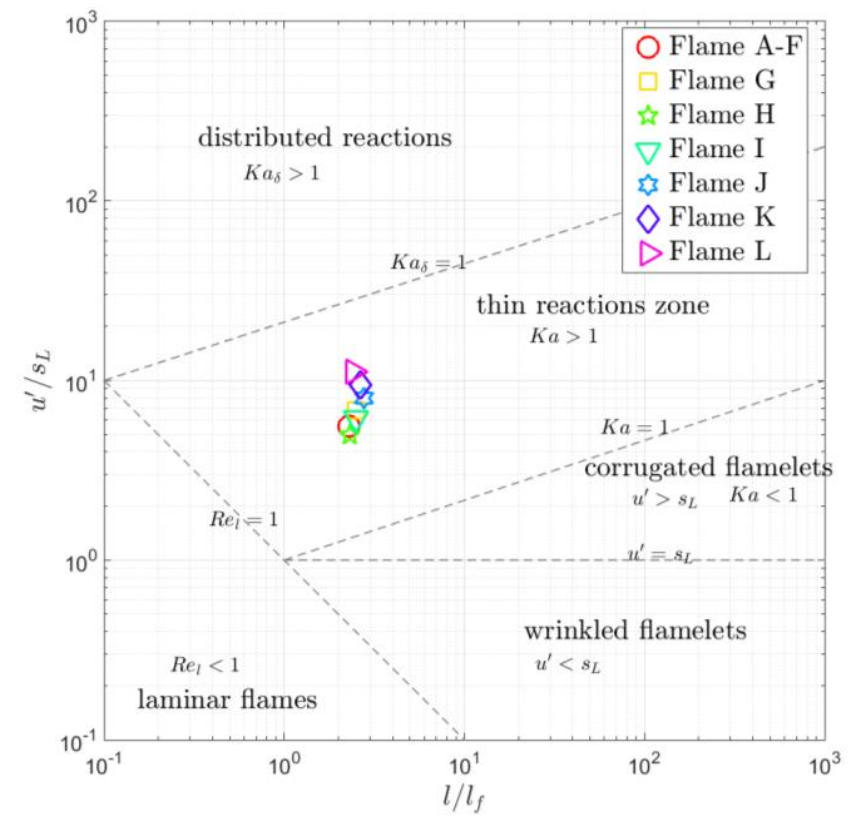

Figure 3: Premixed flame regime location for the flames on the Borghi-Peters diagram.

\section{B. Time-averaged flame structure}

The structure of the flame interaction zone is sensitive to many parameters, including flame spacing $(S)$, Reynolds number, and flame shape. To give a general overview of this sensitivity, results from the time-averaged flame structure of the flames are presented first. Figure 4 shows the flame surface density images obtained from flame edges extracted using the binarization process described in Section II.B.2; these images are the result of stitching together the flame surface densities in the three viewing windows. In all these images, the red lines represent the stitched region between any two FOVs. A weak signal is acquired in the OH-PLIF images for part of FOV III $(40<x<50,15<y<25)$, due to which, inaccurate binarization of the raw images occurs in this region. This leads to inaccurate depiction of the instantaneous flame edge in that particular region. The flame surface density calculations in this region erroneously show the bending of the flame brush towards the centerline of the right burner. Hence, for a direct comparison, this region will not be discussed. Inspection of the flame surface density images for flames A-G (Figure 4(a), (k), (l), (c), (e), (g), (i)) shows that variations in the flame spacing and the bulk flow velocity significantly alters the shape of the flame in the flame interaction zones. Closer flame spacing cases (flames A-C) exhibit additional flame attachment of the inner branches of these flames. This additional flame attachment occurs at the location of the shear layers emanating from the inner walls of the two burners. The presence of the two flames in close proximity of each other changes the temperature distribution in the interaction zone between the two burners. Due to the higher temperatures 
in this region as compared to the cases with farther spacings, this secondary attachment occurs. As the flame spacing is increased, this attachment becomes weak; flame spacings of 45,50 and $55 \mathrm{~mm}$ show that as the burners are separated, the attachement starts to become weak near the burner exit (FOV I). In the flame surface density and chemiluminescence images, this weakening indicates that the flame is only in at the attachment point some of the time, and high-speed OH-PLIF imaging indicates that the flame intermittently attaches and detaches at these intermediary spacings. As the spacing increases, the inner flame edge attachment becomes less frequent, which causes the flame surface density to reduce further, until none is visible in FOV I.

A comparison of bluff-body flames at the wider flame spacing and two different bulk flow velocities shows that flow velocity can also have an impact on the inner branch flame attachment. The inner branch attachment disappears for flames $\mathrm{F}$ and $\mathrm{G}$, which suggests that when the bulk velocity is increased, the mean flow changes the recirculation zone between the two flames and does not allow for the unburned gases to sufficiently undergo a reaction. Normalized time-averaged $\mathrm{CH}^{*}$ chemiluminescence images for flames A, D, E, F and G complement the description of inner branch flame attachment (Figure 4 (b), (d), (f), and (h)). The residence time of $\mathrm{CH}^{*}$ is short in the flame interaction zone; however, it is sufficient enough to mark the inner flame attachment shown in the flame brush images.
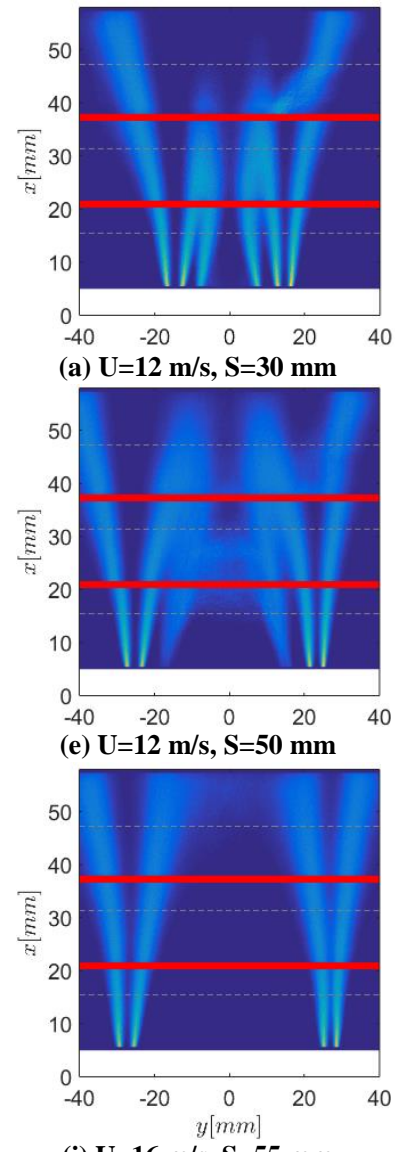

(i) $\mathrm{U}=16 \mathrm{~m} / \mathrm{s}, \mathrm{S}=55 \mathrm{~mm}$

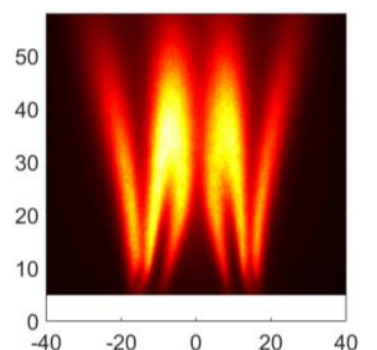

(b) $\mathrm{U}=12 \mathrm{~m} / \mathrm{s}, \mathrm{S}=\mathbf{3 0} \mathrm{mm}$
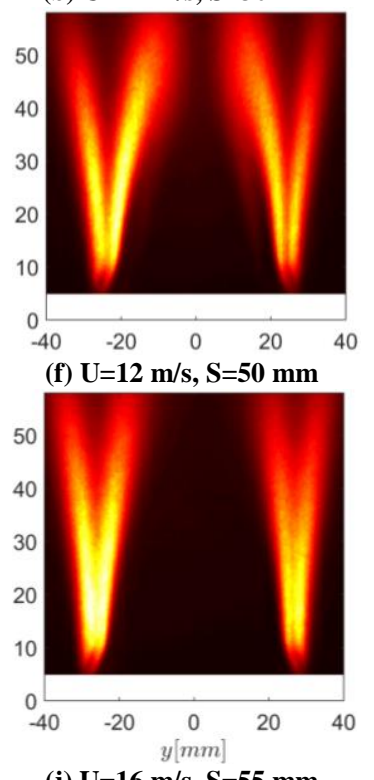

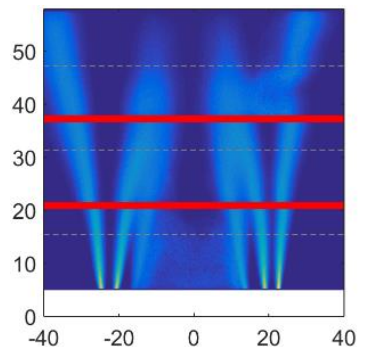

(c) $\mathrm{U}=12 \mathrm{~m} / \mathrm{s}, \mathrm{S}=\mathbf{4 5} \mathrm{mm}$

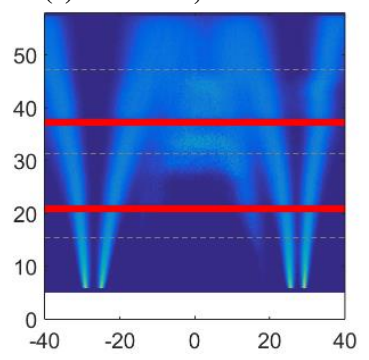

(g) $\mathrm{U}=12 \mathrm{~m} / \mathrm{s}, \mathrm{S}=55 \mathrm{~mm}$

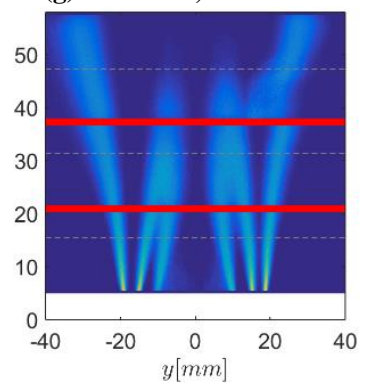

(k) $\mathrm{U}=12 \mathrm{~m} / \mathrm{s}, \mathrm{S}=35 \mathrm{~mm}$
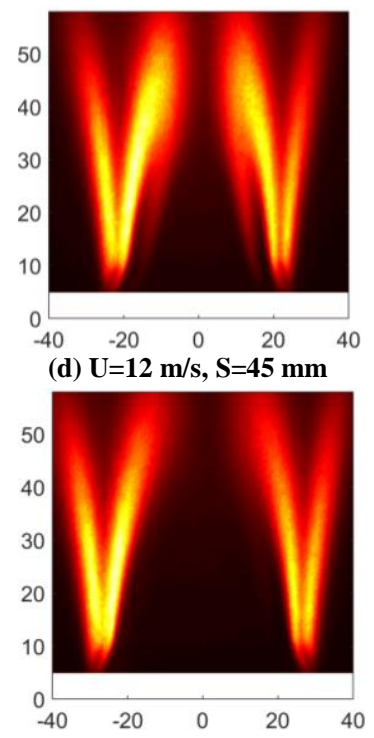

(h) $\mathrm{U}=12 \mathrm{~m} / \mathrm{s}, \mathrm{S}=55 \mathrm{~mm}$

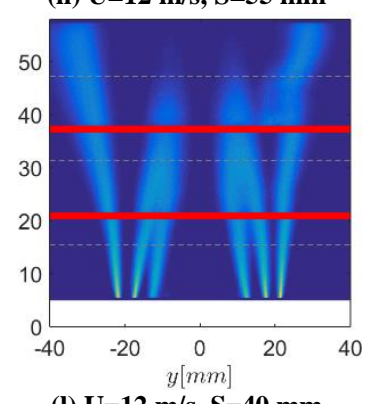

Figure 4: (a)-(j): Flame surface density images and corresponding $\mathrm{CH}^{*}$-chemiluminescence images for flames A, D, E, F, and G. (k)-(l): Flame brush images for flames B and C.

The instantaneous $\mathrm{CH}^{*}$-chemiluminescence images are unable to accurately depict the instantaneous flame-front of these flames in the interaction zones. The instantaneous images have a low signal-to-noise ratio, which does not allow for identifying unburned gases from burned gases. The instantaneous flame edge can be easily identified using the OH-PLIF technique by binarizing the raw images to demarcate the reactants from products. OH radicals in the flame interaction zone in the raw images accumulate in this region, providing a high enough signal-to-noise ratio. This allows us to more accurately obtain the flame fronts and capture the highly unsteady flame attachment phenomena in the flame interaction zones. Figure 5 shows a time-series of raw OH-PLIF images for flames A-F in FOV II. For the

American Institute of Aeronautics and Astronautics 
time-series of each case in this figure, red dashed lines represent the burner centerlines. These raw images are cropped to only focus the interaction regions of these flames, so as $S$ is increased, the burner centerline for the right burner moves out of the figure, specifically for the $S=55 \mathrm{~mm}$ case. As shown in these images, the residual OH in between the two flames allows for capturing the dynamics of the flame-front; smaller flame spacing cases exhibit unburned gas pocket formation in FOV II, while larger flame spacing cases exhibit less unburned gas pocket formation. In all these flames, intersection of the two bluff-body flames does not occur. However, both flames influence the flow-field in between them. Rapid gas expansion across the flames changes the turbulence between the flames, causing the flame structure to alter significantly.

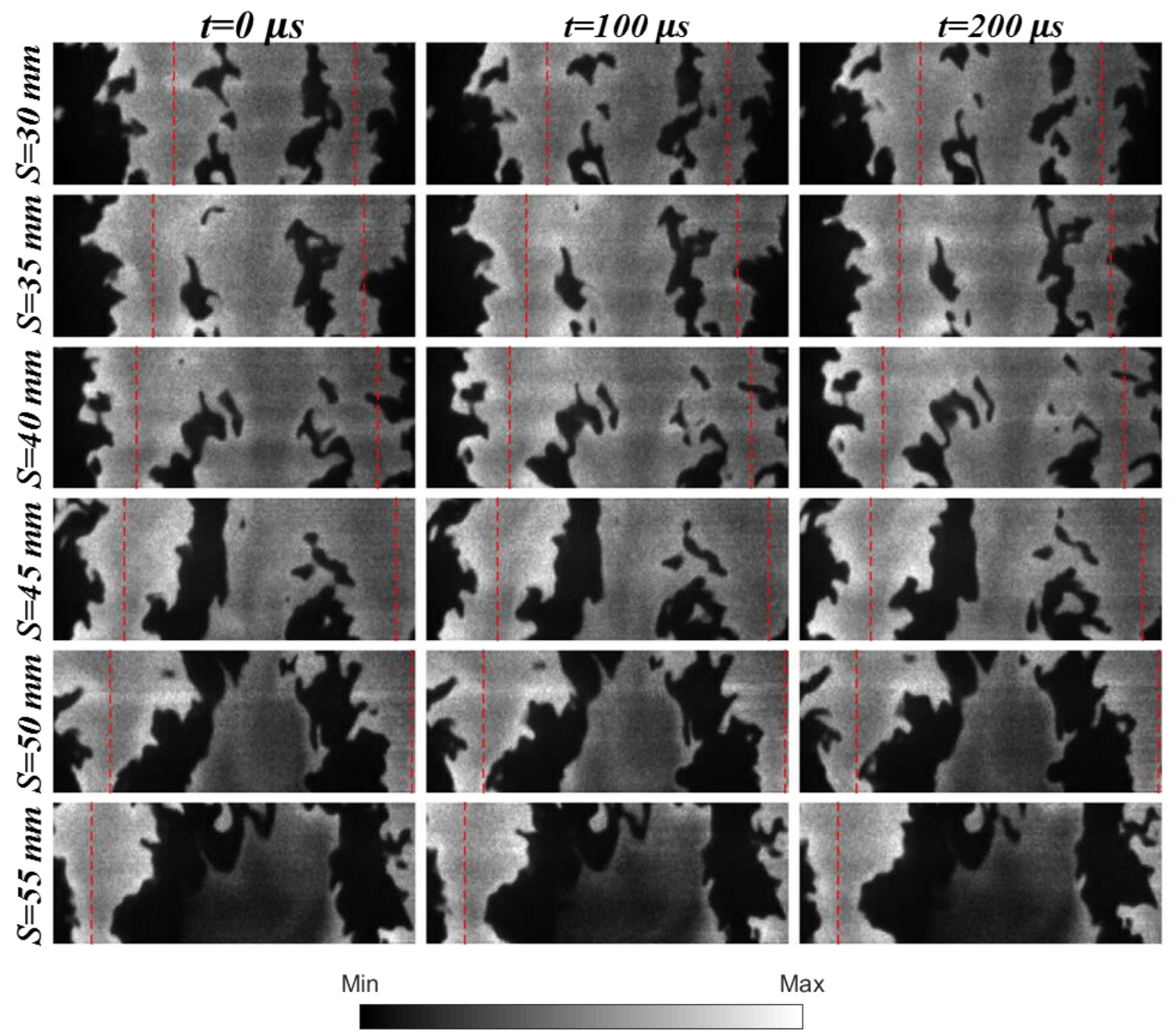

Figure 5: Instantaneous raw OH-PLIF time-sequence images of bluff-body flames in the flame interaction zones (FOV II, Flames A-F). Red dashed lines correspond to the burner centerlines.

Figure 6 shows the instantaneous images for flames F and G in FOV II and III, and highlights the differences between these flames as the bulk flow velocity is increased. Weak flame attachment persists for flame F and unburned gas pockets are formed in FOV III that propagate downstream and are consumed. For Flame G, weak favorable conditions exist between the two flames and no flame attachment occurs. This is evident from the absence of residual $\mathrm{OH}$ radicals between the two flames in Figure 6(b). Additionally, strong flame flapping occurs for these flames, as indicated by the low level intensities in the flame surface density and $\mathrm{CH}^{*}$-chemiluminescnece images in Figure 4(i) and (j). As can be seen in Figure 6(b), this flame exhibits significant wrinkling in the flame interaction zone, where events, such as, convex-normal interactions and tunnel formation occur, leading to a diffuse distribution of the flame brush in this region.

American Institute of Aeronautics and Astronautics 


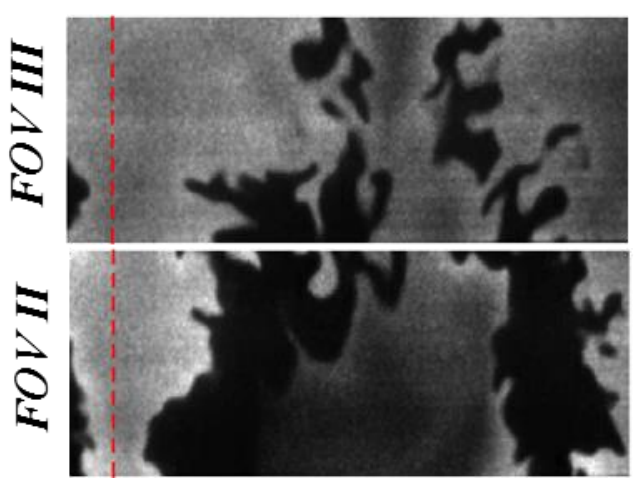

(a) $\mathrm{U}=12 \mathrm{~m} / \mathrm{s}, \mathrm{S}=55 \mathrm{~mm}$

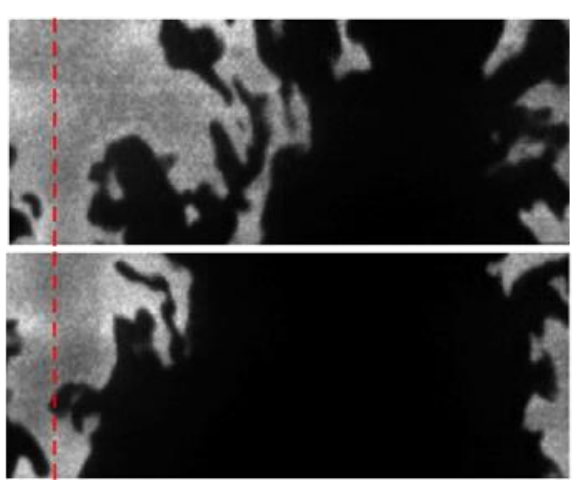

(b) $\mathrm{U}=16 \mathrm{~m} / \mathrm{s}, \mathrm{S}=55 \mathrm{~mm}$

Min

Max

Figure 6: Instantaneous raw OH-PLIF images of flames F and G in FOVs II and III. Red dashed lines correspond to the burner centerlines.

Figure 7 shows the stitched flame surface density images for the five Bunsen flames. In these cases, the flame spacing is kept constant at $30 \mathrm{~mm}$ and the bulk flow velocity is varied from $12 \mathrm{~m} / \mathrm{s}$ to $28 \mathrm{~m} / \mathrm{s}$. The two flames in each case do not intersect; however, the interaction between them can be seen as the inner branches of these flames deflect at different angles as the flow velocity is varied. This deflection is primarily visible in FOVs II and III. As the bulk flow velocity is increased, the inner branches bend towards the experiment centerline in these FOVs.

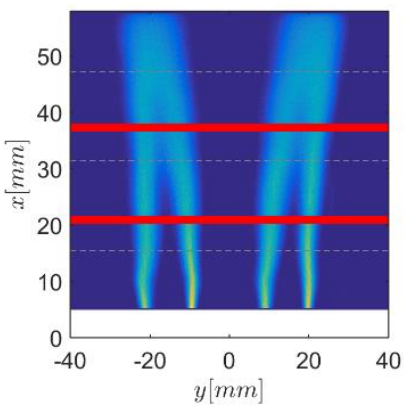

(a) $\mathrm{U}=\mathbf{1 2} \mathrm{m} / \mathrm{s}, \mathrm{S}=\mathbf{3 0} \mathrm{mm}$

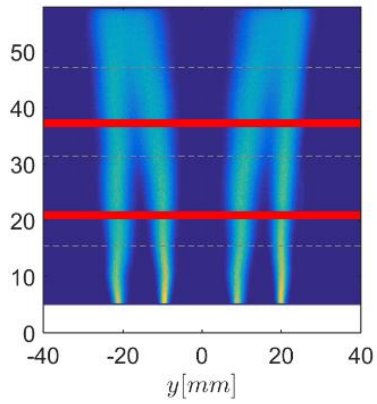

(b) $\mathrm{U}=16 \mathrm{~m} / \mathrm{s}, \mathrm{S}=30 \mathrm{~mm}$

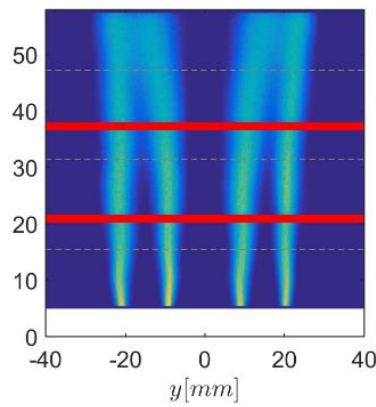

(c) $\mathrm{U}=20 \mathrm{~m} / \mathrm{s}, \mathrm{S}=30 \mathrm{~mm}$

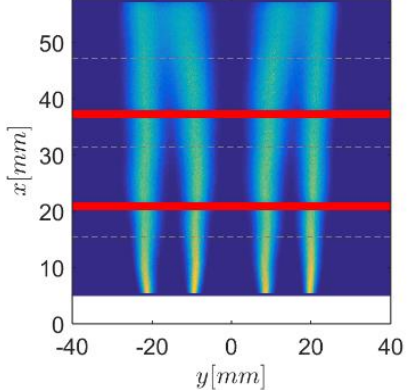

(d) $\mathrm{U}=\mathbf{2 4} \mathrm{m} / \mathrm{s}, \mathrm{S}=30 \mathrm{~mm}$

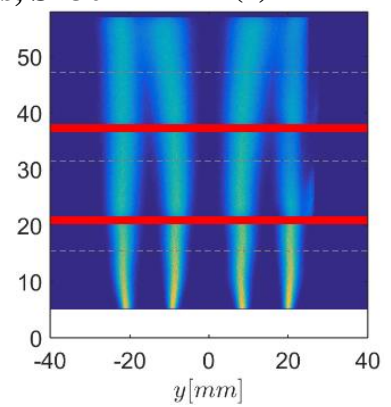

(e) $\mathrm{U}=28 \mathrm{~m} / \mathrm{s}, \mathrm{S}=30 \mathrm{~mm}$

Figure 7: Flame surface density images for Bunsen flames (Flames H-L).

The instantaneous OH-PLIF images for some of these cases are shown in Figure 8. It is evident from these images that the flame height increases as the bulk flow velocity is increased. For flames $\mathbf{J}$ and L, the flame tip is not visible in FOV III, indicating the significant increase in flame height. Increasing the bulk flow velocity also increases the turbulent Reynolds number $\left(R e_{t}\right)$ and causes the flames to wrinkle at a range of scales. Sufficient wrinkling allows for flame-flame interaction events to occur in the shown FOVs in Figure 8; these images show the example of reactant gas pocket formation.

American Institute of Aeronautics and Astronautics 


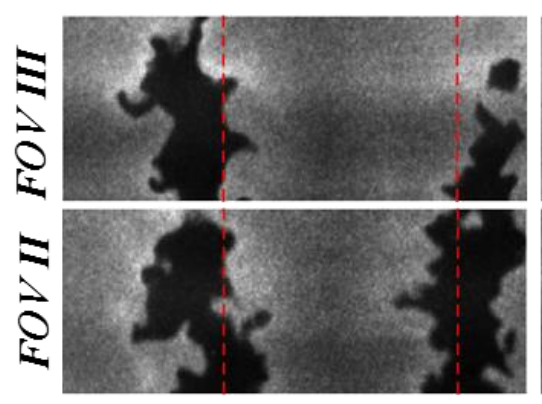

(a) $\mathrm{U}=\mathbf{1 2} \mathrm{m} / \mathrm{s}, \mathrm{S}=\mathbf{3 0} \mathrm{mm}$

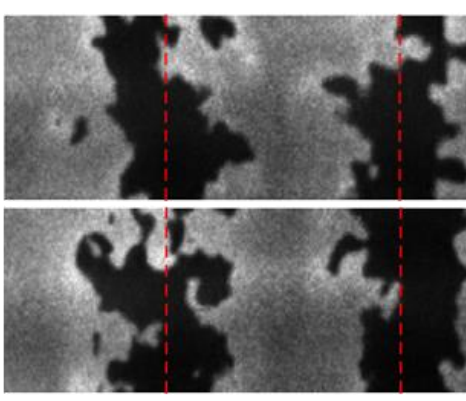

(b) $\mathrm{U}=\mathbf{2 0} \mathrm{m} / \mathrm{s}, \mathrm{S}=30 \mathrm{~mm}$

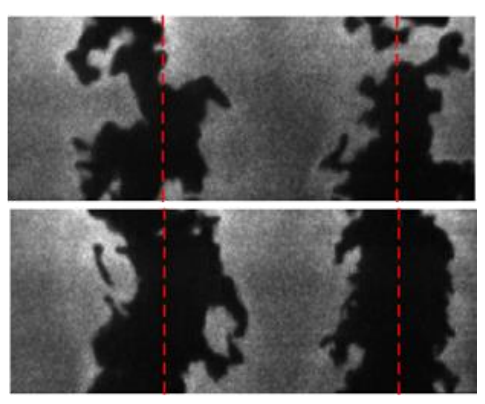

(c) $\mathrm{U}=\mathbf{2 8} \mathrm{m} / \mathrm{s}, \mathrm{S}=\mathbf{3 0} \mathrm{mm}$

Min

$\operatorname{Max}$

Figure 8: Instantaneous raw OH-PLIF images of flames H, J and L in FOVs II and III. Red dashed lines correspond to the burner centerlines.

\section{Flame surface density}

Flame surface density is formulated as the time-averaged flame surface area per unit volume, and is a measure of flame wrinkling [26]:

$$
\mathrm{FSD}=\lim _{\Delta x \rightarrow 0} \frac{\Delta A}{(\Delta x)^{3}}
$$

In this definition, $\Delta A$ is the time-averaged flame area within a cubic volume $(\Delta x)^{3}$. This definition requires the use of three-dimensional imaging techniques, which is not achievable in the current setup. However, two-dimensional imaging techniques have been applied to estimate the flame surface density by imaging planar domains and calculating the time-averaged flame length within the interrogation region [27-30]. Turbulent flames are inherently threedimensional and measurements performed using two-dimensional imaging techniques can inaccurately capture the topology of the flame edge. A DNS study performed by Bell et al. [31] investigated the differences between twodimensional and three-dimensional flame surface density measurements of a laboratory-scale turbulent slot flame. The results from these measurements show a $25-33 \%$ reduction in the flame surface density in the two-dimensional measurement as compared with the three-dimensional measurement.

Cuts from flame surface density images of all the flames investigated here show the local flame structure and how it evolves with downstream distance. Figure 9 shows the horizontal profiles of the flame surface densities taken along the gray dashed lines in Figure 4. The dashed gray lines represent the horizontal centerline of any given FOV. The cross-stream direction in the plots is normalized by the geometric flame spacing $(S)$ to illustrate the similarities and differences in all the flames investigated. One similarity between all bluff-body flames is the thin flame brush near the bluff-bodies, indicating strong flame attachment to the bluff bodies. However, significant differences can still be seen for all the FOVs in the bluff-body flames. The most important differences are in FOV II and III; since the horizontal axis is normalized by the flame spacing $S$, the differences between the flame angles for both flames can be seen when $S$ is increased. Changes in flame angles is evident from moving of the local peaks in the flame brushes towards the burner centerlines. This suggests that when the flame spacing is small, the additional flame attachment promotes a wider spread of the flame branches for both burners; this is likely the result of the enhanced recirculation of fluid between the burners. Additionally, the flame surface density profiles in FOV III show that flame-front wrinkling and flame-flame interaction intensity is increased for larger burner spacing cases. These results suggest that variations in flame spacing can significantly impact the behavior of these flames. Detailed investigation of the instantaneous flame-front dynamics will be part of future work from this experiment, where the sentitivity of flameflame interaction events will be quantified.

American Institute of Aeronautics and Astronautics 

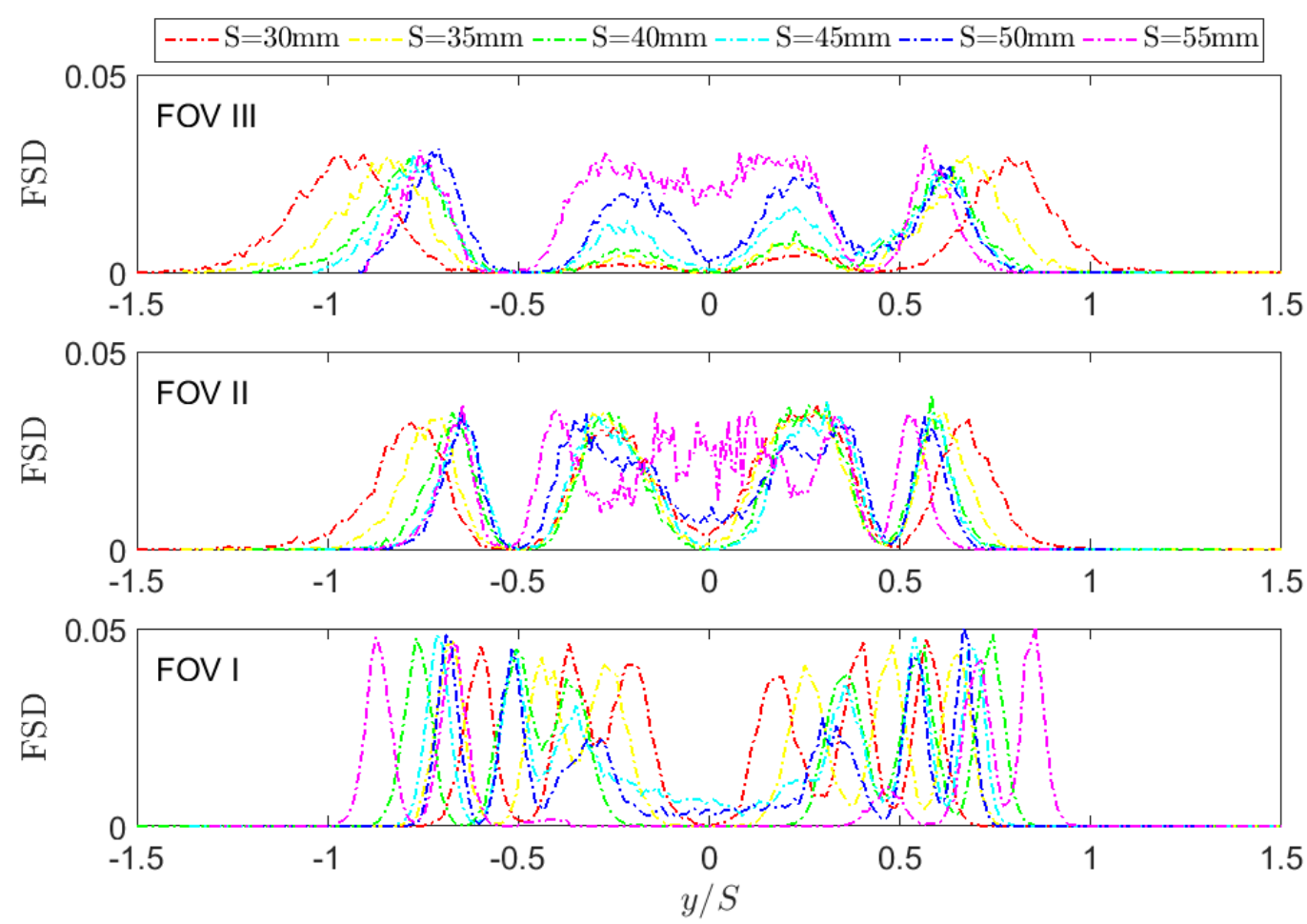

Figure 9: Flame surface density profiles in different FOVs for bluff-body flames (A-F).

The flame surface density contours for Bunsen flames, not shown here, at various bulk flow velocities exhibit very similar behavior in FOV I. Slight differences are noticed in FOVs II and III, where the changes in flame height due to changes in bulk flow velocity start to dominate the time-averaged flame structure. For the lower velocity cases, FOV III exhibits the flame tip region, where reactant gas pockets are formed and consumed. The broadening of the flame surface density for flames H-J in FOV III is indicative of this phenomena.

\section{Flame brush thickness}

Time-averaged progress variables $(\bar{c})$ obtained from the averaging of instantaneous binarized images are utilized to obtain the flame brush thickness. Studies $[32,33]$ have shown that the absolute value of the maximum gradient of the progress variable in the cross-stream direction can be used to approximate the magnitude of the flame brush thickness, as:

$$
\delta_{t}=\max (1 /|(\partial \bar{c}) / \partial y|)
$$

For both bluff-body and Bunsen flames, the inner branch of the left burner flame is used to calculate the flame brush thickness. The inner branches of these flames are directly affected by flame interactions, which makes these branches an interesting choice for direct flame brush thickness comparisons. Figure 10 shows the normalized flame brush thickness as a function of normalized downstream distance. In this figure, the normalization is performed using the flame spacing $S$. The trends for flame brush thickness for the bluff-body flames overlap with each other for the region of $0.1<x / S<0.5$ (near burner exit) and deviate for $x / S>0.5$. This normalized location is indicative of the region where the flame loops and forms the inner flame attachment. The exponential increase in the flame brush thickness is beyond $x / S>0.5$ representing the low gradient values of $\bar{c}$. This is also indicative of the regions where the flame loops and attaches to the burner exit. The magnitude of the flame brush thickness exhibits these difference in flame structures caused due to variation in flame spacing.

American Institute of Aeronautics and Astronautics 


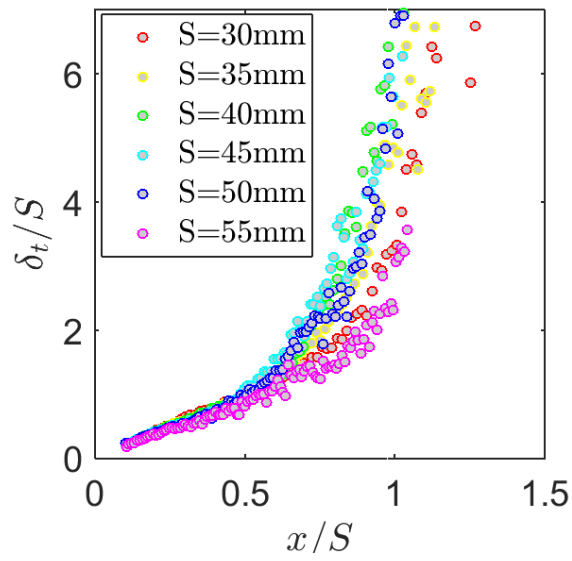

(a) Bluff-body flames

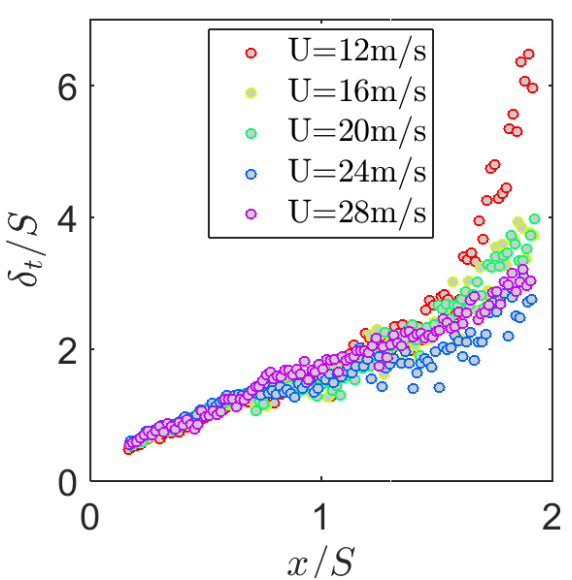

(b) Bunsen flames

Figure 10: Flame brush thickness for (a) bluff-body flames (A-F), and (b) Bunsen flames (H-L). For clarity, every sixth pixel is plotted here.

Figure 10(b) shows the flame brush thickness trends for Bunsen flame cases. Similar to the bluff-body cases, the flame brush thickness for Bunsen flames is also measured along the inner branch of the left burner in each case. For these cases, the trends overlap very well from $0.16<x / S<1.1$ (near burner exit), however, slight deviation is observed beyond $x / S>1.1$ between all the cases. In this region, the effect of variation in flame height dominates the flame brush thickness calculations. The flame heights increase for increasing bulk flow velocity and scattering of the location of the maximum gradient location in the progress variable fields is observed for Flames H-J. Flame tip is not captured in Flames $\mathrm{K}$ and $\mathrm{L}$ in FOV III, which allows for an accurate identification of the maximum gradient location. In both of the flame shapes investigated here, the flame brush thickness trend shows a linear variation with respect to the streamwise direction near the burner exit region. They both exhibit similar slopes and intercepts, indicating a good agreement between the results.

\section{E. Global consumption speed}

The global consumption speed is defined as the total reactant mass flow rate divided by the product of the reactant gas density and area of a defined progress variable contour, as shown below:

$$
S_{T, G C}=\frac{\dot{m}_{R}}{\rho_{R} A_{\bar{c}}}
$$

This definition is applicable in Bunsen-type geometries, where the assumption is that all of the reactant gases pass through the flame. For other geometries, such as the bluff-body stabilized flames, this definition becomes inaccurate, as not all of the reactant gases pass through the flame. For the Bunsen flames studied here, it is not possible to extract a closed $\bar{c}=0.5$ contour with three FOVs when the flame height increases. Hence, for this reason, $\bar{c}=0.1$ is selected for all the cases and the global consumption speeds are calculated accordingly. Figure 11(a) shows the location of $\bar{c}=$ 0.1 for the left burner for flame $\mathrm{H}$. 


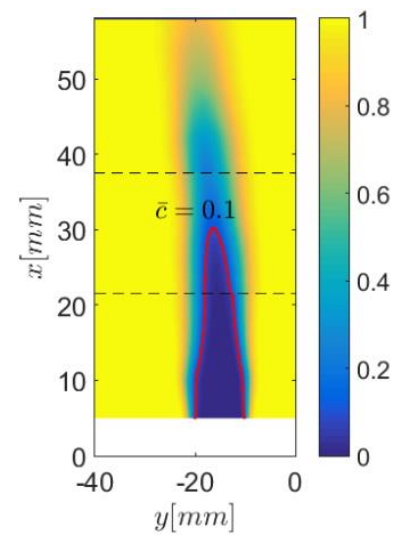

(a)

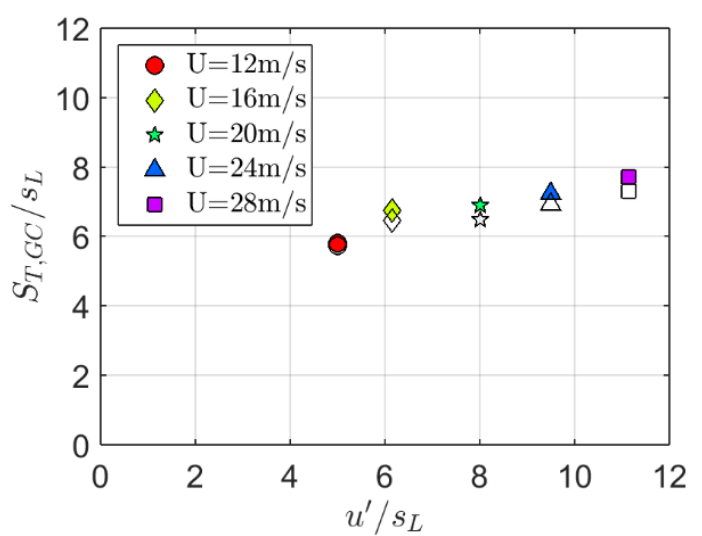

(b)

Figure 11: Global consumption speeds for Bunsen flames: (a) location of the 0.1 averaged progress variable for left burner for $U=12 \mathrm{~m} / \mathrm{s}$ (flame $\mathrm{H}$ ). For obtaining a smooth contour, four pixels are skipped in between two locations; (b) Normalized global consumption speeds for both burners for flames H-L

Figure 11(b) shows the normalized global consumption speeds for both burners for flames H-L. In this figure, the normalization is performed using the laminar flame speed $s_{L}$. The horizontal axis depicts the normalized velocity fluctuations of the reactant gases at the burner exits. Color-filled markers in this figure represent the left burner and the empty markers represent the right burner measurements. The closeness of the two markers for each flame case represent a good agreement between the mass flow rates emanating from the burners. As the total mass flow rate is increased for each burner, the turbulence levels and global consumption speeds linearly increase. The ranges for normalized turbulence intensities presented here falls in the same ranges as Tamadonfar and Gülder [34]. Two different scaling laws are presented in their study based on two values of $\bar{c}$. A visual inspection between the current study and results based on $\bar{c}=0.05$ from Tamadonfar's study show close matching in the ranges of $S_{T, G C} / s_{L}$ values for a similar range of $u^{\prime} / s_{L}$. A recent study by Wabel et al. [35] investigated the effect of extreme values of $u^{\prime} / s_{L}$ on $S_{T, G C} / s_{L}$ for a variety of equivalence ratios and bulk flow velocities. The current study has only investigated a smaller subset of $u^{\prime} / s_{L}$ values compared to their study, and as such, any arguments, such as, saturation of $S_{T, G C} / s_{L}$ results can not be made. This will be included as part of future work, where, flames with higher values of $u^{\prime} / s_{L}$ will be investigated in detail.

\section{F. Flame curvatures}

Flame-front curvature is a geometric parameter that can be measured using two-dimensional imaging techniques, such as OH-PLIF, and describes the topology of the flame front. To calculate the flame curvature from twodimensional measurements, Eq. ( 4 ) is used [11]. Detailed description of how the gradients are obtained is mentioned in Section II.B.3.

$$
\kappa=\frac{\frac{\partial y}{\partial s} \frac{\partial^{2} x}{\partial s^{2}}-\frac{\partial x}{\partial s} \frac{\partial^{2} y}{\partial s^{2}}}{\left[\left(\frac{\partial y}{\partial s}\right)^{2}+\left(\frac{\partial x}{\partial s}\right)^{2}\right]^{3 / 2}}
$$

Figure 12 shows the PDF plots of flame curvatures in three different FOVs for bluff-body and Bunsen flames. To isolate the effects of interacting flames on their topology, we present curvatures conditioned on the inner and the outer branches of the left burner flames. Dashed lines and solid lines in Figure 12 represent the curvature PDFs of the outer and inner branches.

American Institute of Aeronautics and Astronautics 

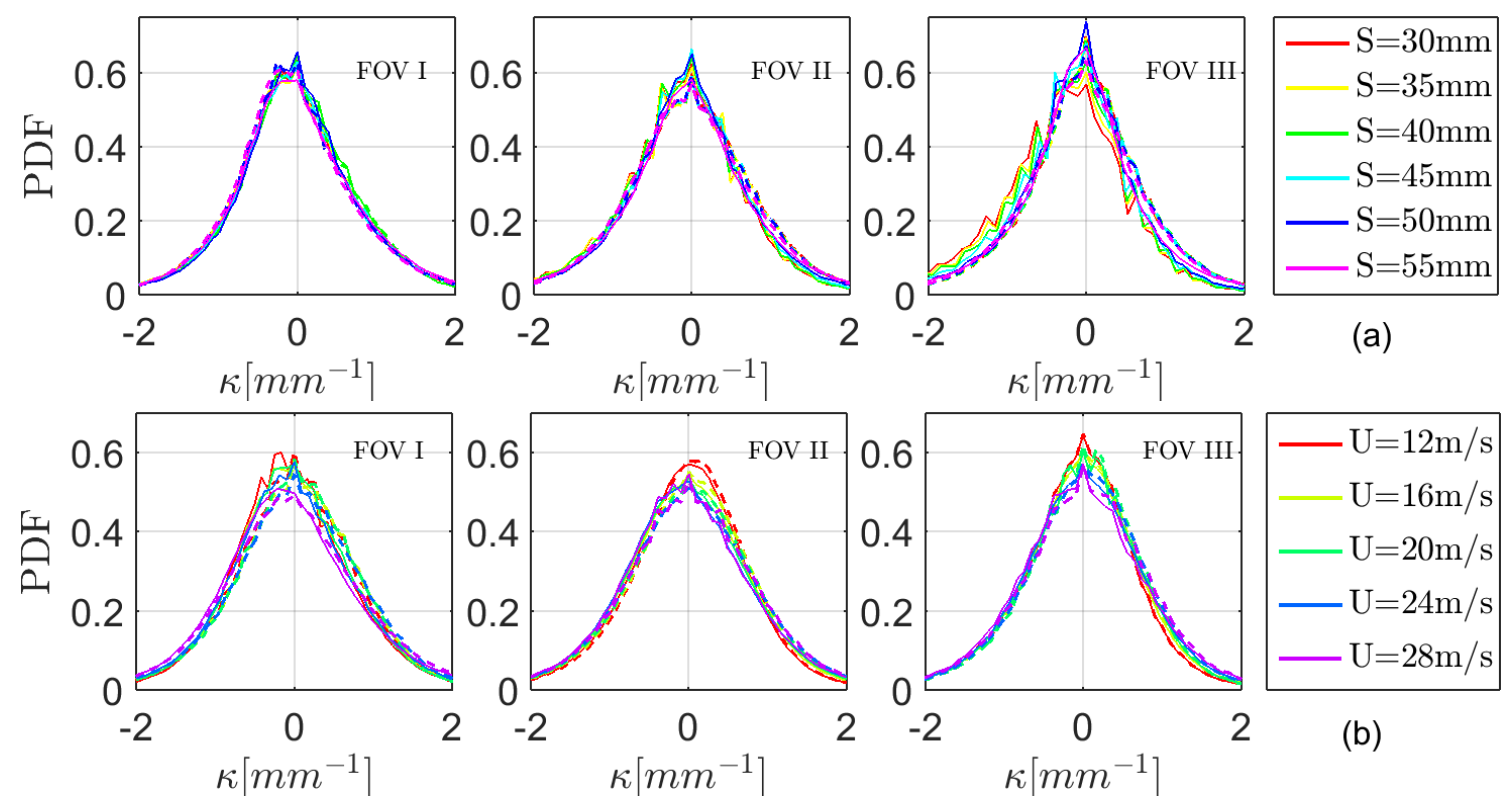

(a)

Figure 12: PDF of flame curvatures in the inner (solid) and outer (dashed) branches for (a) bluff-body (AF), and (b) Bunsen flames (H-L).

Table 2 shows statistics of the PDF of flame curvatures shown in Figure 12. Here, we present the mean of the inner and outer branch curvatures $\left(\bar{\kappa}_{I}\right.$ and $\left.\bar{\kappa}_{O}\right)$ and the pooled standard deviation of the curvatures $\left(s_{\kappa}\right)$. This standard deviation is calculated by collectively calculating the standard deviation of the inner and outer branch curvatures of the flames. Cohen's $d$-metric, as formulated by Cohen [36], is utilized to distinguish the differences in the PDF plots between the inner and outer branches of these flames. The following equation is used to calculate this metric for each case:

$$
d=\frac{\bar{\kappa}_{O}-\bar{\kappa}_{I}}{S_{\kappa}}
$$

Table 2: Statistics of the flame curvature PDF plots.

\begin{tabular}{|c|c|c|c|c|c|c|c|c|c|c|c|c|}
\hline & \multicolumn{4}{|c|}{ FOVI } & \multicolumn{4}{|c|}{ FOVII } & \multicolumn{4}{|c|}{ FOV III } \\
\hline & $\overline{\boldsymbol{\kappa}}_{\boldsymbol{O}}$ & $\overline{\boldsymbol{\kappa}}_{\boldsymbol{I}}$ & $s_{\kappa}$ & $d$ & $\overline{\boldsymbol{\kappa}}_{\boldsymbol{O}}$ & $\overline{\boldsymbol{\kappa}}_{\boldsymbol{I}}$ & $s_{\kappa}$ & $d$ & $\overline{\boldsymbol{\kappa}}_{\boldsymbol{O}}$ & $\overline{\boldsymbol{\kappa}}_{I}$ & $s_{\kappa}$ & $d$ \\
\hline$S=30 \mathrm{~mm}$ & -0.029 & -0.047 & 0.895 & 0.020 & 0.006 & -0.185 & 0.946 & 0.201 & 0 & -0.377 & 0.919 & 0.411 \\
\hline$S=35 \mathrm{~mm}$ & -0.031 & -0.043 & 0.909 & 0.014 & -0.001 & -0.177 & 0.951 & 0.184 & -0.004 & -0.341 & 0.918 & 0.367 \\
\hline$S=40 \mathrm{~mm}$ & -0.030 & -0.047 & 0.888 & 0.019 & -0.005 & -0.159 & 0.928 & 0.167 & -0.002 & -0.301 & 0.919 & 0.326 \\
\hline$S=45 \mathrm{~mm}$ & -0.033 & -0.023 & 0.970 & -0.011 & -0.002 & -0.110 & 0.922 & 0.112 & -0.013 & -0.230 & 0.926 & 0.234 \\
\hline$S=50 \mathrm{~mm}$ & -0.034 & 0.021 & 0.950 & -0.057 & -0.008 & -0.051 & 0.985 & 0.044 & -0.016 & -0.164 & 0.917 & 0.162 \\
\hline$S=55 \mathrm{~mm}$ & -0.032 & 0.016 & 0.970 & -0.049 & -0.010 & -0.010 & 1.165 & 0 & -0.028 & -0.075 & 1.113 & 0.042 \\
\hline$U=12 \mathrm{~m} / \mathrm{s}$ & 0.005 & -0.035 & 0.854 & 0.047 & -0.002 & -0.028 & 0.856 & 0.030 & -0.091 & -0.087 & 0.906 & -0.004 \\
\hline$U=16 \mathrm{~m} / \mathrm{s}$ & 0.008 & -0.037 & 0.880 & 0.051 & 0.008 & -0.022 & 0.920 & 0.033 & -0.040 & -0.054 & 0.883 & 0.016 \\
\hline$U=20 \mathrm{~m} / \mathrm{s}$ & 0.008 & -0.039 & 0.872 & 0.054 & 0.015 & -0.022 & 0.960 & 0.038 & -0.009 & -0.036 & 0.828 & 0.032 \\
\hline$U=24 \mathrm{~m} / \mathrm{s}$ & 0.007 & -0.048 & 0.958 & 0.057 & 0.013 & -0.030 & 0.998 & 0.042 & 0.009 & -0.022 & 0.916 & 0.034 \\
\hline$U=28 \mathrm{~m} / \mathrm{s}$ & 0.005 & -0.043 & 1.100 & 0.044 & 0.011 & -0.032 & 0.979 & 0.044 & 0.010 & -0.028 & 0.928 & 0.040 \\
\hline
\end{tabular}

The means of inner $\left(\bar{\kappa}_{I}\right)$ and outer branch curvatures $\left(\bar{\kappa}_{O}\right)$ for the bluff-body flames investigated in our study are around zero in FOV I and Cohen's $d$-metric $(d)$ is small for this FOV. In FOV II, $\bar{\kappa}_{O}$ values are still close to zero, however, $\bar{\kappa}_{I}$ values are more negative. $d$ in this FOV is larger compared with FOV I, indicating that the inner branches have more negative flame curvatures. Additioanlly, as the flame spacing is increased, $d$ decreases, suggesting that larger variations in flame topologies are seen with cases that have smaller $S$ values. This has also been identified by Worth and Dawson [11]. In FOV III, these variations get larger as $d$ increases for closer flame spacing conditions. These results indicate that bluff-body flames have more negative curvatures in the interaction zones and this effect is larger for smaller $S$ values. Bunsen flames show very similar values of $d$ in FOV I for different velocity conditons, however, the flames show negative values for $\bar{\kappa}_{I}$ compared to $\bar{\kappa}_{O}$. Signs for $\bar{\kappa}_{I}$ and $\bar{\kappa}_{O}$ do not change dramatically for

American Institute of Aeronautics and Astronautics 
FOV II, however, the values of $d$ decrease. Additionally, the value of $d$ increases for increasing velocity cases, indicating that in this region, the flame curvature variation in the inner and outer branches increases with increasing the bulk flow velocity. The values of $d$ decrease further in FOV III, however, the effect of increasing bulk flow velocity on $d$ is similar to FOV II. Results for Busnen flames suggest that near the burner exit, a consistent difference in flame curvatures is seen without any significant variations due to bulk flow velocities, while for flame interaction regions, this difference is affected by the variation in bulk flow velocity and increases as the bulk flow velocity is increased.

\section{Conclusions}

In this paper, geometric and fluid parameters, such as flame shape, flame spacing, and bulk flow velocity are varied to study their effects on the interaction zones of two interacting flames in a dual burner experiment. High bandwidth laser imaging measurements are utilized to capture the flame structures of these flames and statistical parameters are presented.In bluff-body flames, closer flame spacing cases show a preferential attachment of the inner branches of flames in the inner shear layers of the burners, while farther flame spacing exhibits weaker flame attachment. Flame surface densities vary significantly for these cases in the interaction regions, which shows that flame spacing is an important parameter to be considered for the design of multi-flame combustion devices. Flame curvatures results for these flames show that flame branches in the interaction region have more negative flame curvatures than the outer branches. Variations in bulk flow velocities in Bunsen flames show that flame bend outward for low flow velocities and this washes out for high flow velocities. Flame curvature results for these flames suggest that flow velocity is an important parameter in the interaction region as the inner branches show more variations in flame curvatures with increasing flow velocities.

Future work will extend this analysis to quantifying the local effect that interacting flames have in the flame interactions region. Primarily, we will be investigating how local flame-flame merging is influenced with flame spacing and bulk flow velocities. Additioanlly, the effect of these local flame-flame interactions on turbulent flame speed and flame area consumption will be statistically investigated.

\section{Acknowledgments}

This work was supported by the Air Force Office of Scientific Research under Grant FA9550-16-1-0075 with program manager Dr. Chiping Li. The authors gratefully acknowledge Dr. Campbell Carter at the AFRL and LaVision $\mathrm{GmbH}$ for their advice and loan of equipment during these experiments. Additionally, the authors would like to thank Xiaoling Chen, Sean Clees, Wyatt Culler, Michael Meehan, Dr. Bryan Quay, and Dr. Whitney Zimmerman for their contributions to this work.

\section{References}

[1] Hegde, U., Reuter, D., and Zinn, B. "Sound Generation by Ducted Flames," AIAA journal, Vol. 26, No. 5, 1988, pp. 532-537.

[2] Hegde, U., Reuter, D., Daniel, B., and Zinn, B. "Flame Driving of Longitudinal Instabilities in Dump Type Ramjet Combustors," Combustion Science and Technology, Vol. 55, No. 4-6, 1987, pp. 125-138.

[3] Hegde, U., Reuter, D., Zinn, B., and Daniel, B. "Fluid Mechanically Coupled Combustion Instabilities in Ramjet Combustors," 25th AIAA Aerospace Sciences Meeting. 1987, p. 216.

[4] Reuter, D., Hegde, U., and Zinn, B. "Flowfield Measurements in an Unstable Ramjet Burner," Journal of Propulsion and Power, Vol. 6, No. 6, 1990, pp. 680-685.

[5] Francois, I., Larrauri, D., and Escudié, D. "Interaction between Two Premixed Laminar V-Shaped Flame Fronts at Low Lewis Number," Combustion and flame, Vol. 110, No. 1-2, 1997, pp. 14-24.

[6] Dunstan, T., Swaminathan, N., Bray, K., and Kingsbury, N. "Flame Interactions in Turbulent Premixed Twin V-Flames," Combustion Science and Technology, Vol. 185, No. 1, 2013, pp. 134-159.

[7] Dunstan, T., Swaminathan, N., Bray, K., and Kingsbury, N. "The Effects of Non-Unity Lewis Numbers on Turbulent Premixed Flame Interactions in a Twin V-Flame Configuration," Combustion Science and Technology, Vol. 185, No. 6, 2013, pp. 874-897.

American Institute of Aeronautics and Astronautics 
[8] Samarasinghe, J., Peluso, S., Szedlmayer, M., De Rosa, A., Quay, B., and Santavicca, D. "Three-Dimensional Chemiluminescence Imaging of Unforced and Forced Swirl-Stabilized Flames in a Lean Premixed Multi-Nozzle Can Combustor," Journal of Engineering for Gas Turbines and Power, Vol. 135, No. 10, 2013, p. 101503.

[9] Szedlmayer, M. T., Quay, B. D., Samarasinghe, J., De Rosa, A., Lee, J. G., and Santavicca, D. A. "Forced Flame Response of a Lean Premixed Multi-Nozzle Can Combustor," ASME 2011 Turbo Expo: Turbine Technical Conference and Exposition. American Society of Mechanical Engineers, 2011, pp. 883-891.

[10] Dawson, J. R., and Worth, N. A. "Flame Dynamics and Unsteady Heat Release Rate of Self-Excited Azimuthal Modes in an Annular Combustor," Combustion and Flame, Vol. 161, No. 10, 2014, pp. 2565-2578.

[11] Worth, N. A., and Dawson, J. R. "Cinematographic OH-PLIF Measurements of Two Interacting Turbulent Premixed Flames with and without Acoustic Forcing," Combustion and Flame, Vol. 159, No. 3, 2012, pp. 1109-1126.

[12] Worth, N. A., and Dawson, J. R. "Tomographic Reconstruction of $\mathrm{OH}^{*}$ Chemiluminescence in Two Interacting Turbulent Flames," Measurement Science and Technology, Vol. 24, No. 2, 2012, p. 024013.

[13] Aguilar, M., Malanoski, M., Adhitya, G., Emerson, B., Acharya, V., Noble, D., and Lieuwen, T. "Helical Flow Disturbances in a Multinozzle Combustor," Journal of Engineering for Gas Turbines and Power, Vol. 137, No. 9, 2015, p. 091507.

[14] Samarasinghe, J., Culler, W., Quay, B. D., Santavicca, D. A., and O'Connor, J. "The Effect of Fuel Staging on the Structure and Instability Characteristics of Swirl-Stabilized Flames in a Lean Premixed Multinozzle Can Combustor," Journal of Engineering for Gas Turbines and Power, Vol. 139, No. 12, 2017, p. 121504.

[15] Chen, J. H., Echekki, T., and Kollmann, W. "The Mechanism of Two-Dimensional Pocket Formation in Lean Premixed Methane-Air Flames with Implications to Turbulent Combustion," Combustion and flame, Vol. 116, No. 1, 1999, pp. 15-48.

[16] Griffiths, R., Chen, J., Kolla, H., Cant, R., and Kollmann, W. "Three-Dimensional Topology of Turbulent Premixed Flame Interaction," Proceedings of the Combustion Institute, Vol. 35, No. 2, 2015, pp. 1341-1348.

[17] Sun, C., and Law, C. "On the Consumption of Fuel Pockets Via Inwardly Propagating Flames," Symposium (International) on Combustion. Vol. 27, Elsevier, 1998, pp. 963-970.

[18] Ranganath, B., and Echekki, T. "On the Role of Heat and Mass Transport During the Mutual Annihilation of Two Premixed Propane-Air Flames," International journal of heat and mass transfer, Vol. 49, No. 25, 2006, pp. 5075-5080.

[19] Chen, C., and Sohrab, S. "Upstream Interactions between Planar Symmetric Laminar Methane Premixed Flames," Combustion and flame, Vol. 101, No. 3, 1995, pp. 360-370.

[20] Ranganath, B., and Echekki, T. "Effects of Preferential and Differential Diffusion on the Mutual Annihilation of Two Premixed Hydrogen-Air Flames," Combustion Theory and Modelling, Vol. 9, No. 4, 2005, pp. 659-672.

[21] Roach, P. E. "The Generation of Nearly Isotropic Turbulence by Means of Grids," International Journal of Heat and Fluid Flow, Vol. 8, No. 2, 1987, pp. 82-92.

doi: http://dx.doi.org/10.1016/0142-727X(87)90001-4

[22] Gonzalez, R. C., and Woods, R. E. "Digital Image Processing Prentice Hall," Upper Saddle River, NJ, 2002.

[23] Orfanidis, S. J. Introduction to Signal Processing: Prentice-Hall, Inc., 1995.

[24] Peters, N. Turbulent Combustion: Cambridge university press, 2000.

[25] Wabel, T. M., Skiba, A. W., Temme, J. E., and Driscoll, J. F. "Measurements to Determine the Regimes of Premixed Flames in Extreme Turbulence," Proceedings of the Combustion Institute, Vol. 36, No. 2, 2017, pp. 18091816. 
[26] Driscoll, J. F. "Turbulent Premixed Combustion: Flamelet Structure and Its Effect on Turbulent Burning Velocities," Progress in Energy and Combustion Science, Vol. 34, No. 1, 2008, pp. 91-134.

[27] Lipatnikov, A., and Chomiak, J. "Turbulent Flame Speed and Thickness: Phenomenology, Evaluation, and Application in Multi-Dimensional Simulations," Progress in energy and combustion science, Vol. 28, No. 1, 2002, pp. 1-74.

[28] Shepherd, I. "Flame Surface Density and Burning Rate in Premixed Turbulent Flames," Symposium (International) on Combustion. Vol. 26, Elsevier, 1996, pp. 373-379.

[29] Veynante, D., Duclos, J. M., and Piana, J. "Experimental Analysis of Flamelet Models for Premixed Turbulent Combustion," Symposium (International) on Combustion. Vol. 25, Elsevier, 1994, pp. 1249-1256.

[30] Zhang, M., Wang, J., Jin, W., Huang, Z., Kobayashi, H., and Ma, L. "Estimation of 3d Flame Surface Density and Global Fuel Consumption Rate from 2d PLIF Images of Turbulent Premixed Flame," Combustion and Flame, Vol. 162, No. 5, 2015, pp. 2087-2097.

[31] Bell, J. B., Day, M. S., Grcar, J. F., Lijewski, M. J., Driscoll, J. F., and Filatyev, S. A. "Numerical Simulation of a Laboratory-Scale Turbulent Slot Flame," Proceedings of the combustion institute, Vol. 31, No. 1, 2007, pp. 12991307.

[32] Kheirkhah, S., and Gülder, Ö. "Turbulent Premixed Combustion in V-Shaped Flames: Characteristics of Flame Front," Physics of Fluids, Vol. 25, No. 5, 2013, p. 055107.

[33] Namazian, M., Talbot, L., and Robben, F. "Density Fluctuations in Premixed Turbulent Flames," Symposium (International) on Combustion. Vol. 20, Elsevier, 1985, pp. 411-419.

[34] Tamadonfar, P., and Gülder, Ö. L. "Flame Brush Characteristics and Burning Velocities of Premixed Turbulent Methane/Air Bunsen Flames," Combustion and Flame, Vol. 161, No. 12, 2014, pp. 3154-3165.

[35] Wabel, T. M., Skiba, A. W., and Driscoll, J. F. "Turbulent Burning Velocity Measurements: Extended to Extreme Levels of Turbulence," Proceedings of the Combustion Institute, Vol. 36, No. 2, 2017, pp. 1801-1808.

[36] Cohen, J. "Statistical Power Analysis for the Behavioral Sciences (Revised Ed.)." New York: Academic Press, 1977.

American Institute of Aeronautics and Astronautics 